\title{
PENGARUH FRAKSI EKSTRAK DAUN TAGETES (Tagetes erecta) TERHADAP PERTUMBUHAN DAN SPORULASI Colletotrichum capsici SECARA IN VITRO
}

\author{
M Wahyu Satryawibowo, Efri \& Titik Nur Aeny \\ Jurusan Agroteknologi, Fakultas Pertanian, Universitas Lampung \\ Jl. Soemantri Brodjonegoro No.1 Bandar Lampung 35145
}

\begin{abstract}
ABSTRAK
Pada umumnya pengendalian penyakit antraknosa dilakukan dengan menggunakan fungisida kimia sintetik yang selalu menimbulkan dampak negatif. Salah satu alternatif pengendalian yang ramah lingkungan untuk mengendalikan penyakit tanaman adalah menggunakan fungisida nabati. Penelitian ini bertujuan untuk mengetahui efektivitas fraksi ekstrak daun tagetes sebagai fungisida nabati dalam menekan pertumbuhan dan sporulasi patogen antraknosa pada cabai yaitu $C$. capsici secara in vitro. Penelitian ini dilaksanakan di Laboratorium Penyakit Tanaman, Fakultas Pertanian, Universitas Lampung pada bulan Juni sampai dengan September 2014. Rancangan percobaan yang digunakan dalam penelitian ini adalah rancangan acak lengkap (RAL). Percobaan terdiridari enam perlakuan dan lima ulangan. Perlakuan adalah tanpa menggunakan ekstrak (P1), perlakuan dengan fungisida propineb (P2), fraksi ekstrak daun tagetes dengan pelarut air (P3), fraksi ekstrak daun tagetes dengan pelarut metanol (P4), fraksi ekstrak daun tagetes dengan pelarut etil asetat (P5), fraksi ekstrak daun tagetes dengan pelarut n-hexana (P6). Hasil penelitian menunjukkan bahwa fraksi ekstrak daun tagetes dengan pelarut metanol berpotensi sebagai fungisida nabati lebih baik dibandingkan dengan fraksi ekstrak daun tagetes dengan pelarut air dan pelarut etil asetat walaupun pengaruhnya tidak sebaik fungisida propineb terhadap penghambatan pertumbuhan dan sporulasi $C$. capsici secara in vitro.
\end{abstract}

Kata kunci: Cabai, C. capsici, fungisida nabati, tagetes,

\section{PENDAHULUAN}

Cabai merupakan salah satu jenis tanaman sayuran yang memiliki nilai ekonomis tinggi dan cocok dibudidayakan di Indonesia yang beriklim tropik. Buah cabai di sebagian besar wilayah Indonesia digunakan untuk konsumsi dalam keperluan rumah tangga dan sebagian lainnya diekspor dalam bentuk olahan seperti saus, kering, tepung, dan lainnya (BPTP Lampung, 2008).

Gangguan hama dan penyakit merupakan salah satu faktor utama penyebab rendahnya produksi cabai di Indonesia. Salah satu penyakit penting pada tanaman cabai adalah penyakit antraknosa yang salah satu patogennya adalah jamur Colletotrichum capsici L. (Semangun, 2007). Penyakit antraknosa mampu menurunkan hasil produksi pada tanaman cabai mencapai 75\% (Kusandriani dan Permadi, 1996 dalam Syukur et al., 2009).

Salah satu alternatif pengendalian yang ramah lingkungan untuk mengendalikan penyakit tanaman adalah menggunakan fungisida nabati. Tanaman jarak (Ricinus communis) memiliki kandungan bahan aktif seperti saponin, flavonoid,dan alkaloid yang dapat digunakan sebagai fungisida nabati (Asmaliyah et al.,
2010). Tanaman tagetes merupakan tanaman yang diketahui banyak mengandung senyawa kimia seperti saponin, flavonoid, Pepeirton, dan terhtienilnoida (Asmaliyah et al., 2010). Oleh sebab itu, perlu dilakukan pengujian pada tanaman tagetes sebagai fungisida nabati untuk menekan pertumbuhan dan sporulasi jamur $C$. capsici secara in vitro. Penelitian ini bertujuan untuk mengetahui efektivitas fraksi ekstrak daun tagetes sebagai fungisida nabati dalam menekan pertumbuhan dan sporulasi patogen antraknosa pada cabai yaitu jamur C. capsici secara in vitro.

\section{BAHAN DAN METODE}

Penelitian telah dilakukan di Laboratorium Penyakit Tanaman Fakultas Pertanian Universitas Lampung, dimulai dari bulan Juni 2014 sampai dengan September 2014. Bahan-bahan yang digunakan dalam percobaan ini adalah daun tagetes, biakan Colletotrichum capsici, air steril, methanol teknis, etil asetat teknis, n-hexana teknis, klorok $1 \%$, fungisida berbahan aktif propineb $70 \%$, arang aktif, aquades, surfaktan, dan media PSA (Potato succrose agar). Alat yang digunakan diantaranya alat fraksinasi sederhana 
(Gambar 1a), mistar, gelas ukur, handpomp, cawan petri, labu erlenmeyer, autoklaf, alumunium foil, plastik tahan panas, tisu, nampan plastik, plastik wrap, mikropipet, bunsen, cutter, pinset, ose, haemocytometer, mikroskop majemuk, kaca preparat, bor gabus, dan drugalski.

Percobaan terdapat enam perlakuan dan lima ulangan. Perlakuan terdiri dari kontrol/ tanpa menggunakan ekstrak (P1), perlakuan dengan fungisida propineb (P2), fraksi ekstrak daun tegetes dengan pelarut air (P3), fraksi ekstrak daun tagetes dengan pelarut metanol (P4), fraksi ekstrak daun tagetes dengan pelarut etil asetat (P5), fraksi ekstrak daun tagetes dengan pelarut n-hexana (P6). Perlakuan P2, P3, P4, $\mathrm{P} 5$, dan P6 digunakan dengan konsentrasi 1000 ppm dan fungisida yang digunakan mengandung bahan aktif propineb dengan dosis $1 \mathrm{~g} \mathrm{l}^{-1}$. Percobaan disusun menggunakan rancangan acak lengkap (RAL), dan data hasil pengamatan dianalisis dengan sidik ragam (Anova).

Peubah yang diamati pada percobaan ini adalah diameter koloni jamur dan kerapatan spora jamur $C$. capsici. Diameter koloni jamur merupakan indikasi dari pertumbuhan jamur sedangkan kerapatan spora merupakan indikasi dari sporulasi pada jamur. Pengukuran pengamatan diameter koloni dilakukan pada hari ke 2 sampai hari ke 9 setelah inokulasi. Ukuran diameter jamur merupakan rata-rata diameter pengukuran dari empat arah yang berbeda (Gambar 1b). Kerapatan spora dihitung langsung menggunakan haemocytometer. Biakan jamur digenangi dengan aquades untuk mengambil spora dan dikeruk menggunakan drugalski hingga semua spora pada bagian atas permukaan media terlepas. Spora jamur yang telah tercampur dengan aquades dimasukkan kedalam tabung reaksi sampai sebanyak $10 \mathrm{ml}$ (didapatkan suspensi). Kemudian suspensi diaduk sampai homogen dengan menggunakan rotamixer. Setelah suspensi homogen diambil sebanyak $1 \mathrm{ml}$ kemudian diletakkan di atas permukaan Haemocytometer untuk diamati kerapatan spora. Kotak pengamatan yang digunakan adalah kotak sedang. Penghitungan kerapatan spora dilakukan pada 9 hsi (terakhir pengamatan). Kerapatan spora dapat dihitung dengan rumus berikut (Gabriel dan Riyanto, 1989 dalam Herlinda et al., 2006) :

$$
S=\frac{t}{n \times 0,25} \times 10^{6}
$$

Keterangan:

$0.25=$ Konstanta (faktor koreksi penggunaan kotak sampel skala kecil pada haemocytometer).

$\mathrm{S} \quad=$ Kerapatan spora per $\mathrm{ml}$ suspensi

$\mathrm{t}=$ Jumlah total spora dalam kotak sampel pada haemocytometer yang diamati

$\mathrm{n} \quad=$ Jumlah kotak sampel (kotak sedang) pada hamemocytometer yang diamati

\section{HASIL DAN PEMBAHASAN}

Berdasarkan hasil analisis ragam perlakuan pada ekstrak daun tagetes, berpengaruh nyata terhadap pertumbuhan dan sporulasi Colletotrichum capsici
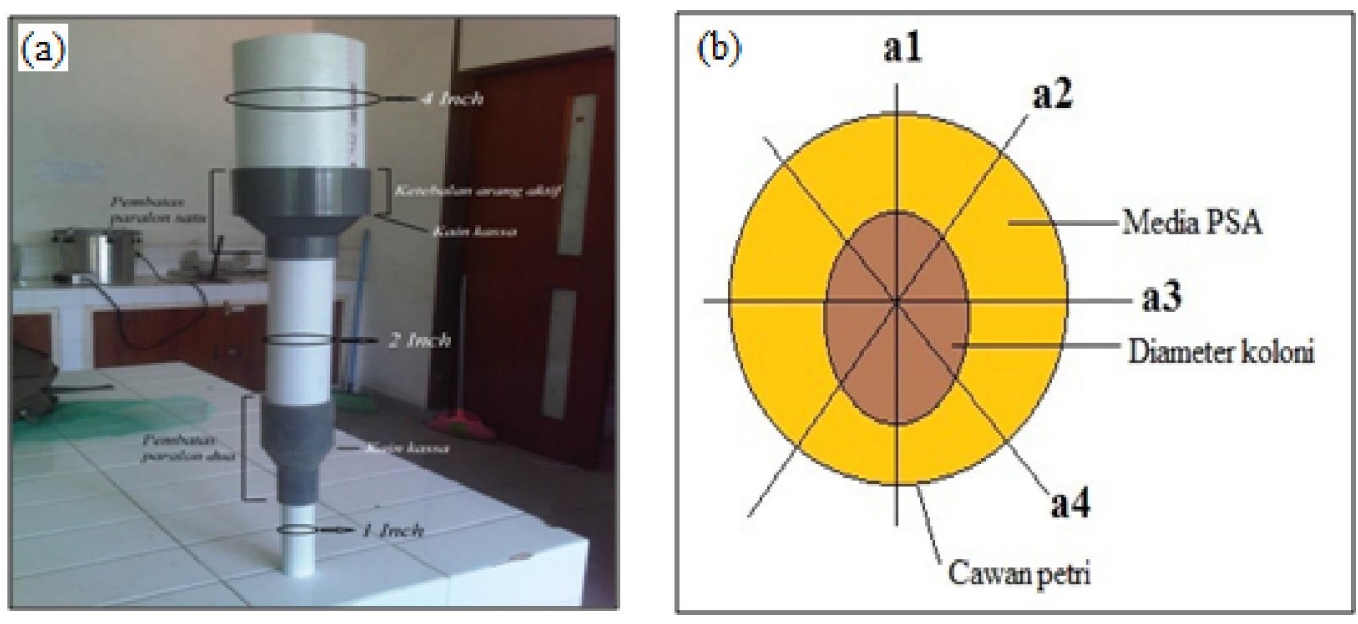

Gambar 1. (a) Alat Fraksinasi Sederhana. Efri, 2014 Komunikasi pribadi. (b) Pengukuran diameter koloni dengan empat arah yang berbeda. a $1=$ arah satu, a $2=$ arah dua, a $3=$ arah tiga, a4 $=$ arah empat. 
secara in vitro. Berdasarkan hasil uji lanjut Duncan (Tabel 1), pengaruh fraksi ekstrak daun tagetes dengan pelarut air, fraksi ekstrak daun tagetes dengan pelarut metanol, dan fraksi ekstrak daun tagetes dengan pelarut etil asetat terhadap diameter koloni jamur C. capsici menunjukkan perbedaan yang nyata terhadap kontrol dan fungisida propineb secara konsisten pada 2 hsi sampai 9 hsi. Fraksi ekstrak daun tagetes dengan pelarut air, fraksi ekstrak daun tagetes dengan pelarut metanol, dan fraksi ekstrak daun tagetes dengan pelarut etil asetat berpotensi sebagai fungisida nabati karena diameter koloni pada ketiga perlakuan tersebut lebih kecil daripada kontrol walaupun tidak dapat menyamai pengaruh dari fungisida propineb. Diantara fraksi ekstrak daun tagetes dengan pelarut air, fraksi ekstrak daun tagetes dengan pelarut metanol, dan fraksi ekstrak daun tagetes dengan pelarut etil asetat, pada fraksi ekstrak daun tagetes dengan pelarut metanol merupakan fraksi ekstrak yang memiliki pengaruh paling baik dan dapat digunakan sebagai fungisida nabati. Sebaliknya pada fraksi ekstrak daun tagetes dengan pelarut n-hexana menunjukkan hasil yang tidak konsisten mulai dari 2 hsi sampai 9 hsi sehingga fraksi ini dianggap kurang berpotensi sebagai fungisida nabati.

Selanjutnya berdasarkan hasil uji Duncan (Tabel 2) pengaruh fungisida propineb, fraksi ekstrak daun tagetes dengan pelarut air, fraksi ekstrak daun tagetes dengan pelarut metanol, fraksi ekstrak daun tagetes dengan pelarut etil asetat, dan fraksi ekstrak daun tagetes dengan pelarut n-hexana terhadap kerapatan spora $C$.

Tabel 1. Pengaruh fraksi ekstrak daun tagetes terhadap diameter koloni $C$. capsici secara in vitro

\begin{tabular}{|c|c|c|c|c|c|c|c|c|}
\hline \multirow{2}{*}{ Perlakuan } & \multicolumn{8}{|c|}{ Rata-rata diameter (cm) pertumbuhan C. capsici pada hari ke (hsi) } \\
\hline & 2 & 3 & 4 & 5 & 6 & 7 & 8 & 9 \\
\hline & & & & & . & & & \\
\hline P1 & $1,290 \mathrm{a}$ & $2,030 \mathrm{a}$ & $2,765 \mathrm{a}$ & $3,415 \mathrm{a}$ & $4,030 \mathrm{a}$ & $4,740 \mathrm{a}$ & $5,325 \mathrm{a}$ & $5,980 \mathrm{a}$ \\
\hline P2 & $0,000 \mathrm{e}$ & $0,000 \mathrm{~d}$ & $0,000 \mathrm{e}$ & $0,000 \mathrm{~d}$ & $0,000 \mathrm{~d}$ & $0,000 \mathrm{f}$ & $0,000 \mathrm{f}$ & $0,000 \mathrm{f}$ \\
\hline P3 & $1,030 \mathrm{c}$ & $1,240 \mathrm{c}$ & $1,605 \mathrm{~d}$ & $1,985 \mathrm{c}$ & $2,360 \mathrm{c}$ & $2,655 \mathrm{~d}$ & $3,015 \mathrm{~d}$ & $3,300 \mathrm{~d}$ \\
\hline P4 & $0,880 \mathrm{~d}$ & $1,190 \mathrm{c}$ & $1,465 \mathrm{~d}$ & $1,795 \mathrm{c}$ & $2,095 \mathrm{c}$ & $2,365 \mathrm{e}$ & $2,610 \mathrm{e}$ & $2,890 \mathrm{e}$ \\
\hline P5 & $1,165 b$ & $1,640 \mathrm{~b}$ & $2,220 \mathrm{c}$ & $2,910 \mathrm{~b}$ & $3,400 \mathrm{~b}$ & $3,870 \mathrm{c}$ & $4,355 c$ & $4,825 c$ \\
\hline P6 & $1,360 \mathrm{a}$ & $1,890 \mathrm{a}$ & $2,525 b$ & $3,320 \mathrm{a}$ & $3,930 \mathrm{a}$ & $4,470 \mathrm{~b}$ & $5,045 b$ & $5,535 \mathrm{~b}$ \\
\hline $\operatorname{Pr}(>\mathrm{F})$ & 0,0001 & 0,0001 & 0,0001 & 0,0001 & 0,0001 & 0,0001 & 0,0001 & 0,0001 \\
\hline
\end{tabular}

Keterangan : $\operatorname{Pr}<0.01=$ Sangat nyata, hsi $=$ hari setelah inkubasi, angka yang diikuti huruf yang sama tidak berbeda nyata setelah diuji dengan Uji Duncan pada taraf 5\%. P1 $=$ kontrol, $\mathrm{P} 2$ = fungisida propineb, $\mathrm{P} 3=$ tagetes dengan pelarut air, $\mathrm{P} 4=$ tagetes dengan pelarut metanol, P5 $=$ tagetes dengan pelarut etil asetat, dan P6 $=$ tagetes dengan pelarut $\mathrm{n}-$ hexana.

Tabel 2. Pengaruh fraksi ekstrak daun tagetes terhadap kerapatan spora $C$. capsici secara in vitro pada 9 hsi.

\begin{tabular}{cc}
\hline Perlakuan & Kerapatan Spora C. capsici $\left(\mathrm{x} 10^{5}\right)$ \\
\hline P1 & $65,07 \mathrm{a}$ \\
P2 & $0,00 \mathrm{~d}$ \\
P3 & $6,40 \mathrm{c}$ \\
P4 & $4,69 \mathrm{c}$ \\
P5 & $24,00 \mathrm{~b}$ \\
P6 & $7,47 \mathrm{bc}$ \\
\hline Pr $(>\mathrm{F})$ & 0,0001 \\
\hline
\end{tabular}

Keterangan: $\operatorname{Pr}<0.01=$ Sangat nyata, angka yang diikuti huruf yang sama tidak berbeda nyata setelah diuji dengan Uji Duncan pada taraf 5\%. Pemberian huruf pada data merupakan hasil transformasi (Lampiran Tabel 27). P1 = kontrol, P2 = fungisida propineb, P3 = tagetes dengan pelarut air , P4 = tagetes dengan pelarut metanol, $\mathrm{P} 5=$ tagetes dengan pelarut etil asetat, dan $\mathrm{P} 6=$ tagetes dengan pelarut n-hexana. 
capsici berbeda nyata dengan kontrol. fraksi ekstrak daun tagetes dengan pelarut air, fraksi ekstrak daun tagetes dengan pelarut metanol, fraksi ekstrak daun tagetes dengan pelarut etil asetat, dan fraksi ekstrak daun tagetes dengan pelarut $n$-hexana berpotensi sebagai fungisida nabati karena dapat menekan kerapatan spora walaupun tidak dapat menyamai pengaruh fungisida propineb. Dari keempat fraksi ekstrak uji fraksi ekstrak daun tagetes dengan pelarut air, fraksi ekstrak daun tagetes dengan pelarut metanol, fraksi ekstrak daun tagetes dengan pelarut etil asetat, dan fraksi ekstrak daun tagetes dengan pelarut n-hexana, fraksi ekstrak daun tagetes dengan pelarut metanol memiliki potensi yang paling baik sebagai fungisida nabati dalam menekan kerapatan spora.

Penghambatan diameter koloni $C$. capsici pada fraksi ekstrak dengan pelarut metanol diduga karena adanya senyawa aktif anti jamur seperti alkaloid, flavonoid, dan poliasetilen. Senyawa-senyawa aktif tersebut memiliki sifat tertentu yang dapat terlarut pada pelarut polar seperti pelarut metanol. Seperti yang dikemukakan oleh Nurjanah et al. (2011), ekstrak kasar metanol kerang pisau mengandung komponen bioaktif berupa komponen alkaloid, steroid, dan flavonoid. Pada kelompok senyawa aktif seperti poliasetilen merupakan senyawa yang bersifat semi polar (Wikanta et al., 2012). Selain itu, Sangi (2008) mengemukakan Saponin memiliki gugus steroid dan triterpenoid sebagai gugus nonpolar, serta memiliki glikosil yang berfungsi sebagai gugus polar. Karena itu saponin memiliki kemungkinan dapat larut pada pelarut metanol. Metanol merupakan pelarut yang bersifat universal sehingga mampu mengikat senyawa aktif pada tanaman yang bersifat polar dan non polar (Houghton dan Raman 1998 dalam Susanti et al.,2012).

Mekanisme kerja bahan aktif pada ekstrak daun tagetes terhadap pertumbuhan dan sporulasi C. capsici pada setiap perlakuan dilakukan pendugaan berdasarkan ratio panjang diameter koloni perlakuan ekstrak tanaman dengan kontrol dan kerapatan spora perlakuan ekstrak tanaman dengan kontrol. Semakin kecil ratio maka pengaruh perlakuan terhadap pertumbuhan diameter atau kerapatan spora semakin besar (Tabel 3).

Tabel 3. Pendugaan mekanisme kerja bahan aktif ekstrak tanaman uji

\begin{tabular}{ll}
\hline Mekanisme Kerja & Kriteria \\
\hline Fungistatik & Jika rasio diameter koloni semakin kecil dan \\
& sebanding dengan ratio kerapatan spora \\
Fungitoksik & Jika rasio diameter koloni dan kerapatan spora \\
& mendekati nol \\
Anti Sporulan & Jika rasio kerapatan spora lebih kecil dari diameter \\
& koloni
\end{tabular}

Sumber: Efri, 2015 (Komunikasi pribadi)

Tabel 4. Persentase diameter koloni dan kerapatan spora C. capsici pada berbagai fraksi ekstrak daun tagetes

\begin{tabular}{cccl}
\hline Perlakuan & $\begin{array}{c}\text { Persentase } \\
\text { diameter koloni } \\
(\%)\end{array}$ & $\begin{array}{c}\text { Persentase } \\
\text { kerapatan spora } \\
(\%)\end{array}$ & $\begin{array}{l}\text { Mekanisme kerja bahan } \\
\text { aktif tanaman }\end{array}$ \\
\hline P1 & 100 & 100 & Fungitoksik \\
P2 & 0 & 0 & Fungistatik \\
P3 & 55,18 & 9,83 & Fungistatik \\
P4 & 48,32 & 7,20 & Fungistatik \\
P5 & 80,60 & 36,88 & Anti Sporulan \\
P6 & 92,47 & 11,47 & .
\end{tabular}

Keterangan: $\%=$ proporsi pertumbuhan/kerapatan spora dibandingkan dengan kontrol. $\mathrm{P} 1=$ kontrol, $\mathrm{P} 2$ = fungisida propineb, $\mathrm{P} 3=$ tagetes dengan pelarut air, $\mathrm{P} 4=$ tagetes dengan pelarut metanol, P5 = tagetes dengan pelarut etil asetat, dan P6 = tagetes dengan pelarut $\mathrm{n}$ hexana. 
Pada ekstrak daun tagetes terhadap pertumbuhan dan perkembangan C. capsici memiliki mekanisme kerja bahan aktif yang berbeda antar perlakuan. Perlakuan kontrol merupakan kontrol sebagai pembanding penentuan mekanisme kerja bahan aktif fungisida terhadap perlakuan fungisida propioneb, fraksi ekstrak daun tagetes dengan pelarut air, fraksi ekstrak daun tagetes dengan pelarut metanol, fraksi ekstrak daun tagetes dengan pelarut etil asetat, dan fraksi ekstrak daun tagetes dengan pelarut n-hexana. Fungisida propineb memiliki kriteria ratio diameter koloni dan kerapatan spora mendekati nilai nol. Dengan demikian bahan aktif fungisida propineb memiliki mekanisme kerja fungitoksik. Fraksi ekstrak daun tagetes dengan pelarut air, fraksi ekstrak daun tagetes dengan pelarut metanol, dan fraksi ekstrak daun tagetes dengan pelarut etil asetat memiliki kriteria ratio diameter koloni sebanding dengan kerapatan spora C. capsici. Dengan demikian bahan aktif fraksi ekstrak daun tagetes dengan pelarut air, fraksi ekstrak daun tagetes dengan pelarut metanol, dan fraksi ekstrak daun tagetes dengan pelarut etil asetat memiliki mekanisme kerja fungistatik. Fraksi ekstrak daun tagetes dengan pelarut $\mathrm{n}$-hexana memiliki kriteria ratio kerapatan spora lebih kecil dari diameter koloni $C$. capsici. Dengan demikian bahan aktif fraksi ekstrak daun tagetes memiliki mekanisme kerja anti sporulan (Tabel 4).

\section{KESIMPULAN}

Dari hasil penelitian yang telah dilakukan dapat disimpulkan bahwa fraksi ekstrak daun tagetes dengan pelarut air, pelarut metanol, dan pelarut etil asetat dapat menekan pertumbuhan dan sporulasi $C$. capsici secara in vitro. Fraksi ekstrak daun tagetes dengan pelarut metanol merupakan fraksi paling efektif diantara fraksi yang lain walaupun keefektifannya tidak sama dengan fungisida propineb dalam menekan pertumbuhan dan sporulasi C. capsici secara in vitro.

\section{DAFTAR PUSTAKA}

Asmaliyah, H., E. E. Wati H., S. Utami, K. Mulyadi, Yudhistira, \& F. W. Sari. 2010. Pengenalan Tumbuhan Penghasil Pestisida Nabati dan Pemanfaatannya Secara Tradisional. BPPK. Pusat Penelitian dan Pengembangan Produktivitas Hutan. Palembang.
BPTP Lampung. 2008. Teknologi Budidaya Cabai Merah. Balai Pengkajian Teknologi Pertanian. Bandar Lampung.

Herlinda, S., M. D. Utama, Y. Pujiastuti, \& Suwandi. 2006. Kerapatan Dan Viabilitas Spora Beauveria bassiana (Bals.) Akibat Subkultur Dan Pengayaan Media, Serta Virulensinya Terhadap Larva Plutella xylostella (Linn.) J. HPT Tropika $6(2): 70-78$

Nurjanah, L. Izzati, \& A. Abdullah. 2011. Aktivitas Antioksidan dan Komponen Bioaktif Kerang Pisau (Solen spp). Ilmu Kelautan. 16 (3) : 119124

Sangi, M., M.R.J. Runtuwene, H.E.I. Simbala, \& V.M.A. Makang. 2008. Analisis Fitokimia Tumbuhan Obat di kabupaten Minahasa Utara. Chem. Prog. 1(1):47-53.

Semangun, H. 2007. Penyakit-Penyakit Tanaman Hortikultura di Indonesia. Gadjah Mada University Press. Yogyakarta. Hlm 52-57

Susanti, A.D., D. Ardiana, G. Gumelar P., \& Y. Bening G. 2012. Polaritas Pelarut sebagai Pertimbangan dalamPemilihan Pelarut Untuk Ekstraksi Minyak Bekatul dariBekatul Varietas Ketan (Oriza sativa glatinosa). Simposium Nasional RAPI XI FT $U M S$. Universitas Sebelas Maret Surakarta. Surakarta.

Syukur, M., S. Sujiprihati, J. Koswarah, \& Widodo. 2009. Pewarisan Ketahanan Cabai (Capsicum annum L) terhadap Antraknosa yang disebabkan oleh Colletotrichum acutatum. Bul. Agron. 35 (2) : $112-117$

Wikanta, T., D. Gusmita, L. Rahayu, \& E. Marraskuranto. 2012. Kajian Awal Bioaktivitas Ekstrak Etanol dan Fraksinya dari Spons Callyspongia sp. Terhadap Sel Lestari Tumor HeLa. JPB Perikanan. 7 (1) : 1-10 